\title{
Design and Analysis of a Mechanical Ventilation System Based on Cams
}

\author{
J. Alan Calderón Ch.a,b , Carlos Gianpaul Rincón Ruizb, Bray Jesús Martin Agreda Cardenas ${ }^{\mathrm{b}}$, \\ Juan José Jiménez de Cisneros y Fonfría ${ }^{b^{*}}$ \\ a Angewandte Nanophysik, Institut für Physik, Technische Universität Ilmenau, Ilmenau 98693, Germany \\ b Engineering Department, Pontificia Universidad Católica del Perú, Lima 15088, Perú; \\ alan.calderon@pucp.edu.pe (J.A.C.Ch.); rinconr.carlos@pucp.pe (C.G.R.R.); b.agreda@pucp.edu.pe \\ (B.J.M.A.C.).
}

* Correspondence: juanjose.cisneros@pucp.pe (J.J.J.F.); Tel.: +51-1-626-2000

\begin{abstract}
A mechanical ventilation system is a big support for breathing complications, in which an external solution is quite necessary to keep oxygen compensation in the patients. Its knowledge is well widespread and different equipment has been developed. However, they are very expensive and their quantity in medical centers is not sufficient, especially in Peru. Hence, it has been required to develop new methods to provide oxygen by a low cost equipment; Protofy, a research group from Spain, designed one of the first low cost mechanical ventilation systems which was medically validated by its government. In this sense, a redesign of the mechanical ventilation system was carried out according to the local requirements and available technology, a different airbag resuscitator with different properties and geometry, but maintaining its working concept based on a cam compression mechanism. Sensors and a display were added to improve the performance with a control algorithm for the rotation frequency and to show the ventilation curves over time to the medical staff. It was necessary to develop a mathematical model to relate the behavior between ventilation curves for a patient and physical variables of the design, especially in the epidemic COVID 19, that many countries are dealing with at the time research is being conducted. The mechanical ventilation system was redesigned, fabricated, and tested measuring its ventilation curves over time. Results indicate that this redesign provides a sturdy equipment able to work during a longer lifetime than the original. The replicability of the ventilation curves behavior is assured, while the mechanism dimensions are adapted for a particular airbag resuscitator. The mathematical model of the whole system can predict satisfactorily the ventilation curves over time and was used to provide the air pressure, volume, and flow as a function of the rotation angle measured by sensors.
\end{abstract}

Keywords: mechanical ventilation design; low cost mechanical ventilator; experimental ventilation curves; mechanical ventilation mathematical model; COVID-19

\section{Introduction}

The first ventilator prototypes were studied many years ago aiming to supply mechanical ventilation for patients [1], furthermore, to solve the "artificial respiration" problem under emergencies such as respiratory insufficiency. Artificial respiration continued to be in development owing to be a big support for medical doctors. During the last century, poliomyelitis was a big problem for the world. One of its complications was having trouble breathing, therefore, artificial respiration proved to be a useful solution. However, in parallel to the development of big artificial respiration equipment, practical models were researched and designed. One of these models was 
known as "Pulmotor [1]", which supplied oxygen to the patient by periods. Moreover, new concepts for artificial breathing equipment were proposed, such as mixing $\mathrm{CO} 2$ with oxygen for patient treatment. Notwithstanding, this particular application was analyzed carefully before developing commercial models owing to avoid the excess of $\mathrm{CO} 2$ in the patient.

Although mechanical ventilators have already been used and the knowledge of its system is widespread as explained, they are very expensive for the average household income and its quantity in medical centers is not sufficient either in Peru [2]. The use of a mechanical ventilator based on an airbag resuscitator compression mechanism has been widespread since one of the first functional prototypes was introduced in [3]. In this context, different compression mechanisms were developed: developed by Protofy [4], OxyGEN was one of the first low-cost mechanical ventilators to be medically validated in Spain. This was the reason to redesign this ventilator to respond to the different requirements in Peru, but keeping its working concept and dimensions well established by them, in order to obtain the same ventilation curves: pressure, volume and flow over time.

\section{Materials and Methods}

\subsection{Description of the mechanical ventilation system OxygenIP.PE}

OxygenIP.PE is a low-cost mechanical ventilator based on an airbag resuscitator compression mechanism for inducing an airflow to the patient. The system was designed to provide a volume control ventilation (VCV). Figure 1a,b show the ventilation system isometric views and Figure 1c shows the fabricated second prototype of the OxygenIP.PE ventilation system. This is a modified version of the OxyGEN mechanical ventilator developed by Protofy [5].

The original working concept developed by Protofy [5] was maintained due to the satisfactory medical results previously obtained by them in pre-clinical tests for animals and humans [4]. Its working concept consists of a DC motor which transmits torque and rotation to a cam, this cam drives an oscillating follower, which in turn compresses an airbag in order to increase the air pressure inside and produce an air flow to the patient. The provided ventilation curves to the patient depends on the cam's shape; in this sense, five cams are fabricated following an algorithm developed by Protofy [6]. The cam is changed manually according to the ventilation requirements established by the medical staff.

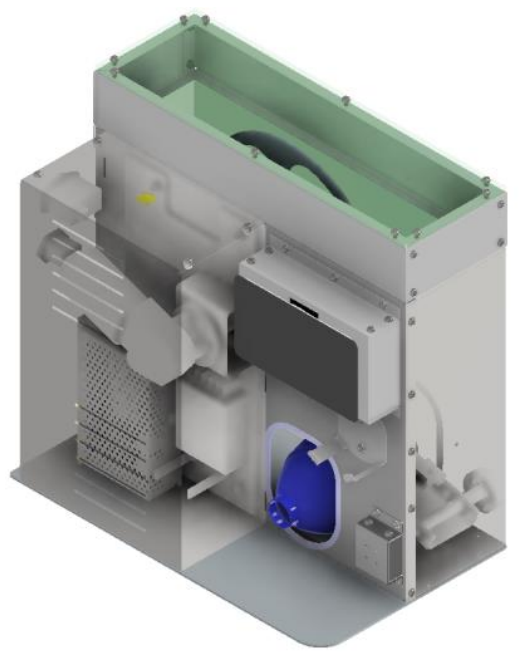

(a)

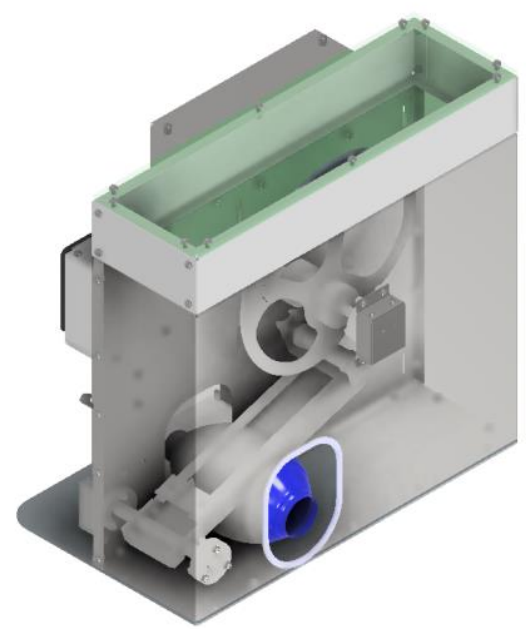

(b) 


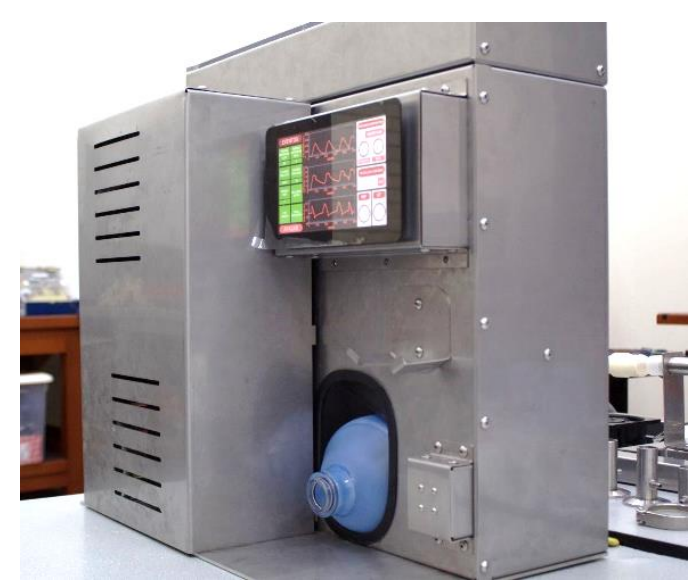

(c)

Figure 1. Mechanical ventilation system OxygenIP.PE

\subsection{Components redesign considerations}

The original OxyGEN project uses simple components for fabrication available in its country such us a DC motor from a wiper washer as mechanical power source. Although most of these components were available in Peru, some of them were not due to a reduction of international imports and international demand rise in early March because of COVID 19 pandemic, especially electronic components and the airbag resuscitator. The use of different components and air bag resuscitator lead to change the mechanical ventilation system behavior and ventilation curves. Hence, a redesign of components was carried out in order to obtain ventilation curves as similar as possible to the original.

The redesign also seeks to get a sturdier equipment, with a longer lifetime and the possibility of mass production with the available technology in metal mechanical workshops in Peru because one of the objectives was to develop an equipment able to be used in small medical centers in remote places, where this technology is not currently available. Additionally, electronic components were added to improve performance and develop a control algorithm which allows to get a more sophistical device for providing useful information to medical staff.

\subsubsection{Power sources}

Figure 2a shows a section view of the OxygenIP.PE where power sources are installed, a 12V@20A power supply to energize the ventilator, a DC motor Valeo $12 \mathrm{~V}$ previously used as wiper washer motor to provide torque and rotation to the cam compression mechanism and a 5V@5A power supply for the Raspberry pi 7" display.

\subsubsection{Airbag compression mechanism}

Figure $2 \mathrm{~b}$ shows the compression mechanism inside the ventilation system. It consists of a cam mounted on the DC motor shaft, an oscillating follower pivoted with its end fixed to the wall of ventilator case. An airbag resuscitator BESMED BE-2100 1600mL was used instead of an Ambu bag resuscitator (originally used in the OxyGEN project), due to the shortage in our country.

The oscillating follower and bearing supports were redesigned having in mind the possibility of mass production and a longer lifetime using local technology available in Peru. To comply with medical material requirements, AISI $308 \mathrm{~S}$ stainless steel was used. The roller shaft sits on bearings which allow its rotation but restrict translation movements, and is also fixed to the oscillating follower. The roller is also covered with vulcanized rubber, in order to reduce friction, vibrations and noise in operation for a better control and use of the DC motor. 


\subsubsection{Electronic components and control system}

Sensors were implemented to measure the angular position of the motor shaft and the oscillating follower shaft over time for a control algorithm. This keeps the rotating frequency of the motor shaft over the transitory working condition. As the airbag is compressed, the DC motor needs to provide a high torque due to the increase of pressure, this behavior affect the rotation frequency over time, hence the respiratory frequency changes and this affects negatively the performance.

During early March, neither differential pressure sensors, nor absolute pressure sensor (both used to obtain ventilation curves) were available. In this sense, the angular position also allows to predict the ventilations curves using a calibrated mathematical model developed in this research. After a transduction stage, signals from sensors are sent to the display to show the ventilation curves which bring useful information to the medical staff. If the absolute pressure and differential pressure sensors were available, they could have been be implemented to the breathing circuit and connected to the display more easily.

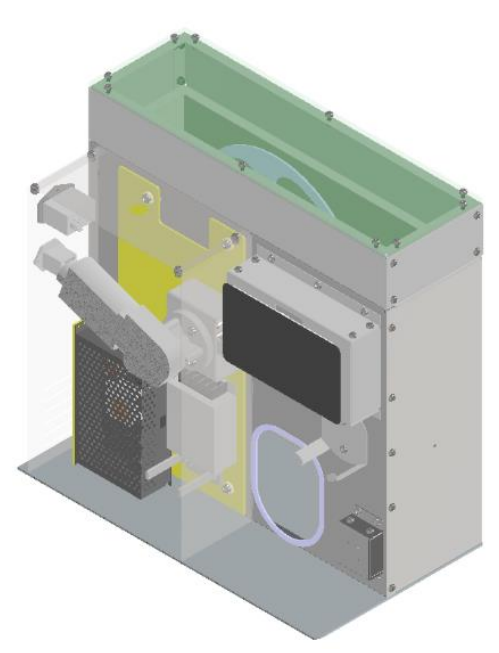

(a)

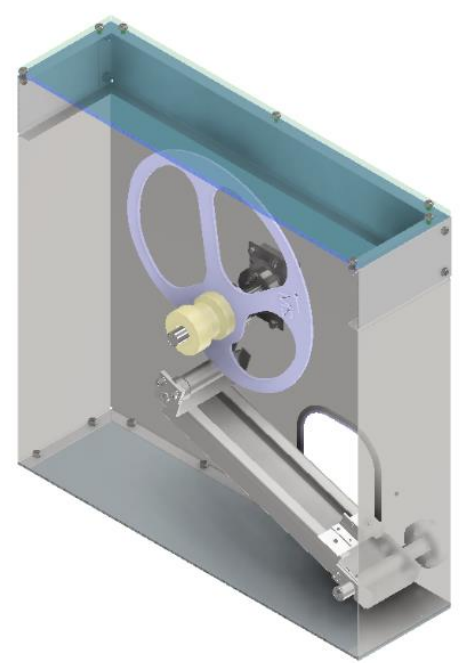

(b)

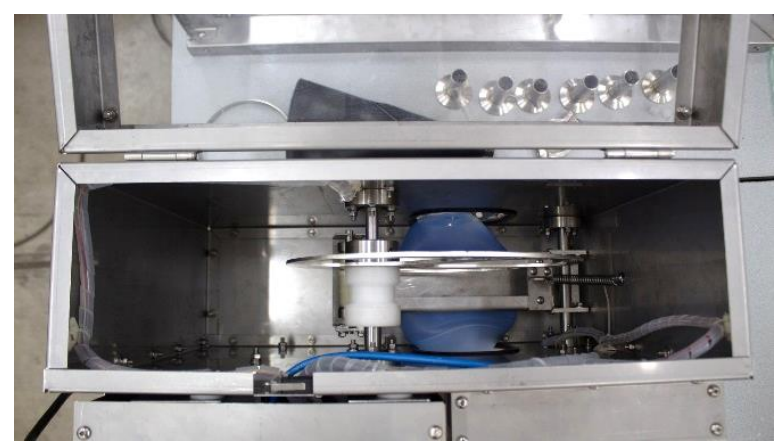

(c)

Figure 2. Section views of the mechanical ventilation system OxygenIP.PE: (a) A section view of the electric components; (b) A section view of the compression mechanism; (c) A superior view of the fabricated ventilator 


\subsection{Compression mechanism and cam shape analysis}

The starting mechanism was designed by Protofy [6]. In order to replicate standard ventilation curves: pressure, volume and flow over time, it is necessary to have knowledge of the dynamical behavior to relate physical variables, such as dimensions, distances and positions, to ventilation parameters. Figure 3 shows a dynamical model of the cam-oscillating follower mechanism, where $\mathrm{O} 3$ and $\mathrm{O} 1$ are the rotation centers of the cam and follower respectively, C1 and C2 are vertical and horizontal distances between centers, respectively.

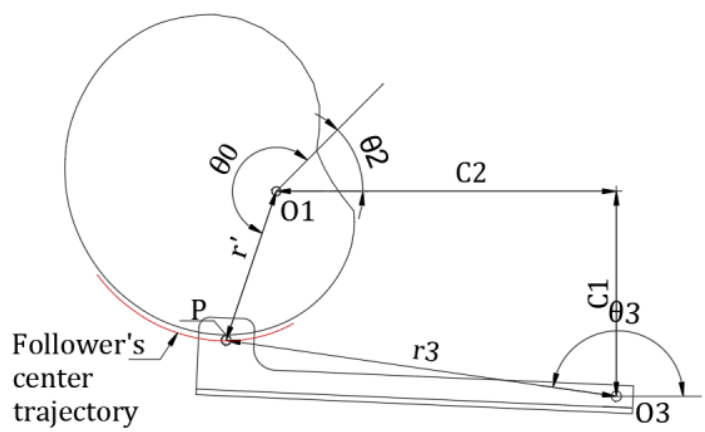

Figure 3. Compression mechanism model

While the follower and cam's shape are in contact, their movements are related, this is achieved by a spring inside the ventilator case. From the model, the following equations which govern the mechanism kinematics are obtained. Hence, the angular position of the oscillating follower is calculated over time if all dimensions are established.

$$
\begin{gathered}
r^{\prime} \cos \theta_{p}-r_{3} \cos \theta_{3}=C_{2} \\
r^{\prime} \operatorname{sen} \theta_{p}-r_{3} \operatorname{sen} \theta_{3}=C_{1} \\
\theta_{p}=\theta_{2}+\theta_{0}
\end{gathered}
$$

The equations can also be used to generate the cam shape; however, the relation between $\theta_{2}$ and $\theta_{3}$ are previously required. This relation is obtained from the volume over time curves required for the patient and the volume over rotation angle curves which can be determine by prototype testing.

$$
\begin{gathered}
V=f(t) \\
V=g\left(\theta_{3}\right)
\end{gathered}
$$

Since the volume as a function of the oscillating follower rotation is difficult to obtain, an approximation of the cam radius as a function of cam rotation angle allows to determine the primitive angle corresponding to the radius, so the shape coordinates are calculated, this is well developed in the Protofy's MATLAB algorithm [6]. For a better approximation, the radius as a function of cam rotation angle can also be used to solve the three equations above and the cam shape can be obtained.

\subsection{Mathematical modeling of the mechanical ventilation system}


Describing the breathing process is a very complex task. To do that, a detailed analysis of the physical variables involved in the transfer of mechanical energy in the artificial mechanism is needed. This way, it is possible to determine the relation between these physical variables from the mechanism and the ventilation parameters, which is finally the aim of the machine. Figure 4a describes the physical variables of the airbag while Figure $4 \mathrm{~b}$ show its equivalent as an open loop in order to prepare a mathematical model to organize every variable involved in the mechanical ventilation system. The force " $F$ ", produced by the oscillating follower to the airbag, induces pressure on the airbag ( resuscitator), as consequence, the air exits the bag and is goes into the mechanical ventilation system with a pressure "P" and an air volume flow " $\underline{d V}_{d t}$ " (Figure 4a). The process above is depicted by inlet variables " $U$ " into the system " $\mathrm{X}$ " and responses " $\mathrm{Y}$ " (Figure $4 \mathrm{~b}$ )

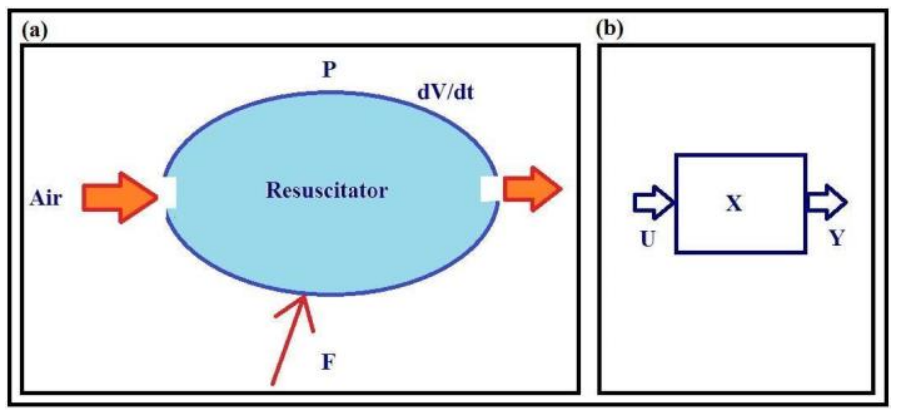

Figure 4. Breathing scheme.

\subsubsection{Procedure description}

The following flowchart, depicted by Figure 5, summarizes the mathematical model designed (chapter above) to obtain an estimate of the parameters and physical variables involved in the mechanical ventilator. The main target of the algorithm is to get the estimate of the mechanical ventilator parameters "air volume, air pressure and air volume flow" relevant for the artificial breathing of patients. For this task, it is necessary to define certain variables and parameters which are conditions for the polynomial model (modulating function proposed in this research). The obtained mathematical model was then calibrated or "corrected" with experimental data averaging different parameters with assigned weights.

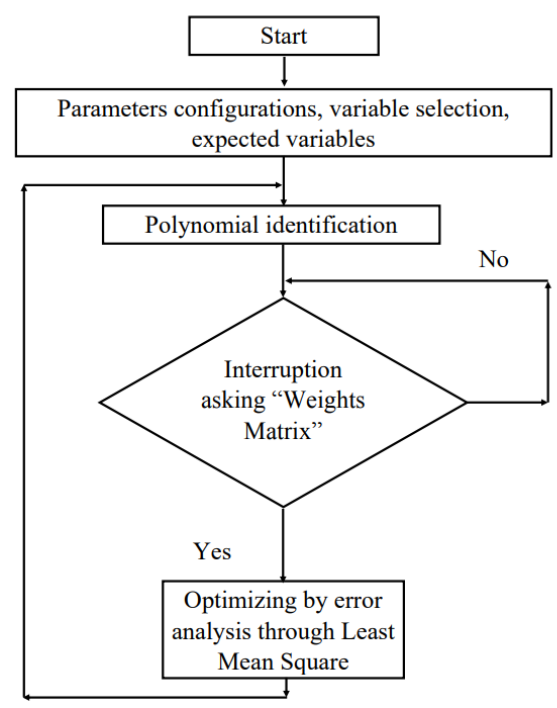

Figure 5. Algorithm for physical parameters estimation for the mechanical ventilation system based on cams 
The geometrical parameters for a general cam (an element that causes the force over the airbag) are represented in Figure 6, where $\mathrm{Q}$ is the "curvature radius", " $\mathrm{r}$ " is the rotational displacement, " $\omega$ " is the rotational speed, [7].

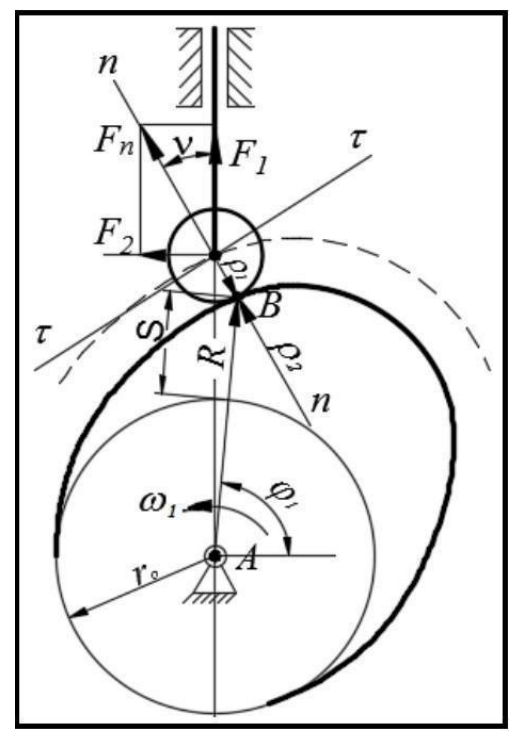

Figure 6. The dynamical model for a general cam[7].

Equation (6) represents the energy transmission from the cam movement Mc to the energy that needs the volume control Mvc to proportionate oxygen to the patient. However, losses during energy transmission are considered.

$$
M_{c}=M_{v c}+\text { losses }
$$

Equation (7) is proposed for the energy balance, " $\mathrm{f}$ " is the function that depends on the cam rotational speed " $\omega$ ", the contact area " $\mathrm{s}$ ", and pressure transmission " $\mathrm{P}$ ", furthermore the volume flow " $\mathrm{dv} / \mathrm{dt}$ " and losses $\gamma$.

$$
f_{w, s, P}+\frac{d v}{d t}=\gamma
$$

In this context, equation (8) proposes the pressure as function of " $\mathrm{s}$ ", cam mass " $\mathrm{M}$ " and curvature radius " $\mathrm{Q}$ ".

$$
P(t)=f(s, M, \rho)
$$

For which, the curvature radius is described by equation (9), and " $r$ " is the rotational displacement [7].

$$
\rho=\frac{\left(r^{2}+\left(\frac{d r}{d t}\right)^{2}\right)^{\frac{3}{2}}}{r^{2}+2\left(\frac{d r}{d t}\right)^{2}-r \frac{d^{2} r}{d t^{2}}}
$$

By other side, the "diffusion equation" is described by equation (10) [8]. 


$$
\frac{\partial P}{\partial t}=D \frac{\partial^{2} P}{\partial x^{2}}+\mu \frac{\partial P}{\partial x}+\beta(P-P b)=\Gamma
$$

And a theoretical solution given by " $\mathrm{P}(\mathrm{x}, \mathrm{t})$ " is shown by equation (11).

$$
P(x, t)=\frac{4 P_{0}}{\pi} \sum_{n=0}^{\infty} \frac{1}{2 n+1} e^{-D \frac{\pi^{2} t}{l^{2}}}\left(\frac{(2 n+1) \pi x}{l}\right)
$$

And solution of the equation above is the volume flow that is described by equation (12).

$$
\frac{\partial V}{\partial t}=\left(\frac{\delta P}{R}\right) e^{-\frac{t}{\tau}}
$$

Therefore, by correlating the last two equations as "Modulating Functions" a general solution can be described: equation (13). Furthermore, this equation was widely used in the older dynamical analysis [8], [9] and [10].

$$
P^{n} y(t)+\sum_{j=1}^{n} a_{j} P^{n-j} y(t)=\sum_{j=1}^{n} b_{j} P^{n-j} u(t)+e(t)
$$

However, as stated by the "Modulating Function solution analysis for diffusion equation" [8], [9] and [10], with this methodology, the diffusion equation was solved to get models adapted for specific applications. By obtaining the solutions of the coefficients, it can be possible to get information of the geometrical, thermal and mechanic parameters which can be adjusted to different necessities and applications in fluid mechanics. That is the reason why the Modulating Function in this analysis gives plenty of strategies. The equation (14) describes "space fractional advection dispersion equation" $c$.

$$
\frac{\partial c(x, t)}{\partial d t}+v(x) \frac{\partial c(x)}{\partial d x}-d(x) \frac{\partial c(x)^{\alpha}}{\partial d x^{\alpha}}=r(x, t)
$$

Therefore, proposing equation (15) to find solutions for the mechanical fluid variables [8], [9] and [10].

$$
\frac{\partial^{\alpha}}{\partial x^{\alpha}} f(x)=\frac{1}{\Gamma(n-\alpha)} \frac{d^{n}}{d x^{n}} \int_{x=0}^{x}(x-t)^{n-\alpha-1} f(t) d t
$$

in which, having "g" as the "Modulating function", it can be possible to further reduce equations such as described in equation (16).

$$
\int_{x=0}^{I} g(I-x) \frac{\partial^{\alpha}}{\partial x^{\alpha}} f(x)=\int_{x=0}^{I} \frac{\partial^{\alpha}}{\partial x^{\alpha}} f(I-x) d x
$$

Furthermore, a reduced differential equation is given in equation (17)

$$
\frac{\partial^{\alpha}}{\partial x} \frac{\partial^{\alpha} f(x)}{\partial x^{\alpha}}=\psi_{o}(n-\alpha) \frac{\partial^{\alpha}}{\partial x} \frac{\partial^{\alpha} f(x)}{\partial x^{\alpha}}-G
$$


In which, "G" is given by the equation (18)

$$
G=\frac{1}{\Gamma(n-\alpha)} \frac{d^{n}}{d x^{n}} \int_{x=0}^{x}(x-t)^{n-\alpha-1} \ln (x-t) f(t) d t
$$

Finally, to solve the diffusion equation, the coefficients of the general diffusion equation are given by equation (19)

And equation (20)

$$
v(x)=\sum_{k=1}^{k_{o}} v_{k} f_{k}(x)
$$

$$
d(x)=\sum_{k=1}^{k_{o}} p k f_{k}(x)
$$

Therefore, by linear algebra (because of the Modulating Functions solutions) in equation (21)

$$
Q X=Y
$$

In which "Q" is given by equation (22)

$$
Q=\left(\begin{array}{ccccc}
q_{11} & q_{12} & q_{13} & \ldots & q_{1 k_{1}+k_{2}} \\
q_{21} & q_{22} & q_{23} & \ldots & q_{2 k_{1}+k_{2}} \\
\vdots & \vdots & \vdots & \ldots & \vdots \\
\vdots & \vdots & \vdots & \vdots & \vdots \\
q_{M 1} & q_{M 2} & q_{M 3} & \ldots & q_{M k_{1}+k_{2}}
\end{array}\right)
$$

Also " $X$ " is described by equation (23)

$$
X=\left(\begin{array}{c}
v_{1} \\
v_{2} \\
v_{3} \\
\vdots \\
v_{k 1} \\
d_{1} \\
d_{2} \\
d_{3} \\
\vdots \\
d_{k 2}
\end{array}\right)
$$


Furthermore " $\mathrm{Y}$ " is given by equation (24)

$$
Y=\left(\begin{array}{c}
y_{1} \\
y_{2} \\
y_{3} \\
\vdots \\
y_{M}
\end{array}\right)
$$

The equation (25) is proposed to obtain every component " $q$ " from equation (22)

$$
q_{m, k}=\left\{\begin{array}{lc}
\int_{x=0}^{L_{1}} \frac{\partial f k(x) \varphi_{m}\left(L_{1}-x\right)}{\partial x} c(x, t) d x & , k=1,2, \ldots, k_{1} \\
\int_{x=0}^{L_{1}} \frac{\partial^{\alpha}(x) \varphi_{m}(x)}{\partial x} c\left(L_{1}-x, t\right) d x & , k=k_{1}+1, \ldots, k_{1}+k_{2}
\end{array}\right.
$$

Moreover, the solution " $y$ " is given by equation (26)

$$
y_{m}=-\int_{x=0}^{L_{1}} \varphi_{m}\left(L_{1}-x\right)\left(r(x, t) \frac{\partial c(x, t)}{\partial t}\right) d x
$$

In which $\varphi$ is described by equation (27)

$$
\varphi_{m, k}\left(L_{1}-x\right)=p_{k}(x) \varphi_{m}\left(L_{1}-x\right)
$$

Therefore, the optimal parameters " $X$ " are obtained through equation (28)

$$
X=\left(Q^{T} Q\right)^{-1} Q^{T} Y
$$

Nevertheless, to adapt the estimates of desired parameters it is necessary to analyze the error between the desired answer and the expected or measured values. Equation (29), where solution error analysis " $e(t)$ " is the discrete error, and " $V$ " keeps the Fourier series coefficients [8], [9] and [10], tasks this issue.

$$
e_{n}(m)=\sum_{k=m}^{n+m} \alpha\left(k, m, \theta_{a}\right) V(k)
$$

Furthermore, $\alpha$ is the frequency parameter function that is described by equation (30)

$$
\alpha\left(k, m, \theta_{a}\right)=C_{k}-m \sum_{j=0}^{n} a_{j}\left(j k w_{o}\right)^{n=j}
$$

For which, the nonlinear model for error analysis is given in equation (31)

$$
\sum_{j=0}^{n_{1}} \sum_{k=1}^{n_{2}} g_{j(\theta)} F_{j k}(u, y) P_{j k}(p) E_{k}(u, y)=0
$$

Hence, the cost function described through equation (32) given to enhance the parameters $\theta$ [8], [9] and [10]. 


$$
J(\theta)=\sum_{j=0}^{n_{1}} \sum_{k=0}^{n_{2}} r_{j k} g_{j}(\theta) g_{k}(\theta)
$$

Also, according to get "parameters of the main model" the derivation is described by equation (33)

$$
\frac{\partial J}{\partial \theta}=(Y-\Gamma \theta)^{T} W^{-1}(Y-\Gamma \theta)
$$

Where parameters are showed in equation (34), as dependent of the "adaptive" coefficients

$$
\theta=\left(\Gamma^{T} W^{1} \Gamma\right)^{-1} \Gamma^{T} W^{-1} Y
$$

For which, the optimal response is given by equation (35)

$$
\hat{Y}=X\left(X^{T} X\right)^{-1} X^{T} \Upsilon
$$

And the adaptive optimal solution (to achieve the parameters) is obtained through equation (36). For this reason, all the parameters which are looking for the estimated answer of the mechanical ventilator through the adaptive matrix weight "W" [8], [9] and [10].

$$
\hat{\beta}=X\left(X^{T} W X\right)^{-1} X^{T} W \Upsilon
$$

Therefore, Figure 7 shows the pressure (blue color curve) in $\mathrm{cmH} 2 \mathrm{O}$, the air volume flow (red color curve) and the volume (green color curve) which were obtained by the mathematical analysis described by equations explained in paragraphs above.

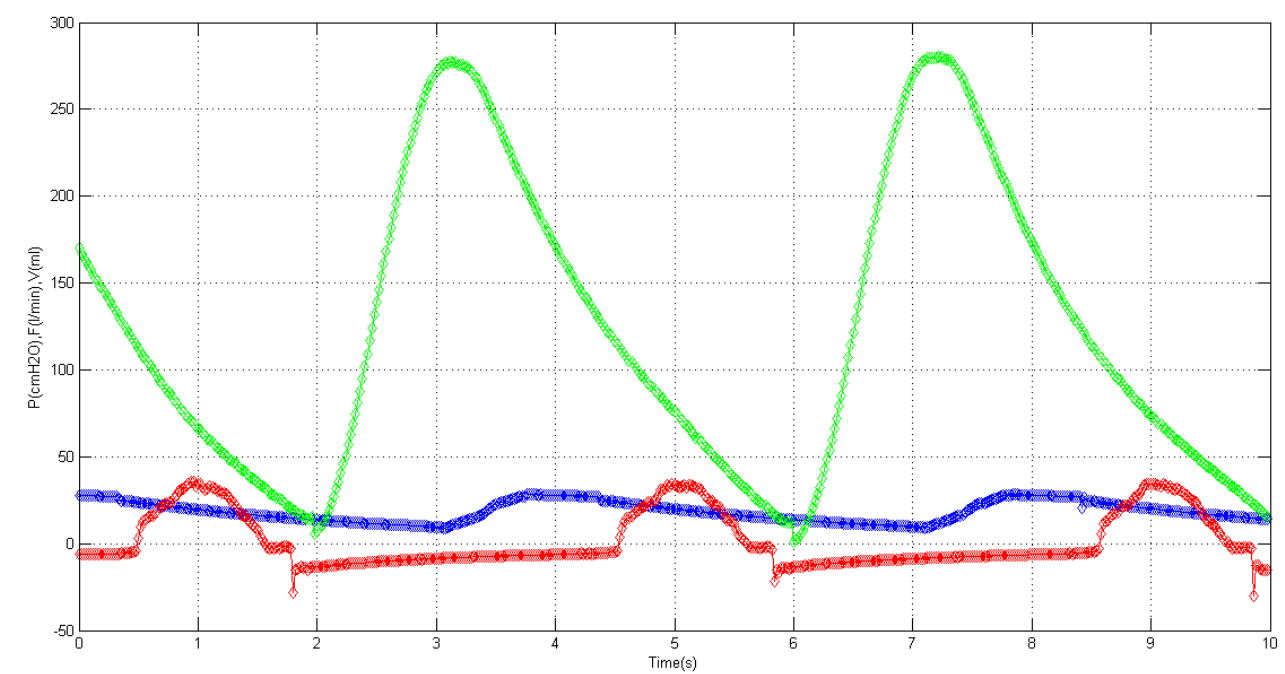

Figure 7. Pressure, volume flow and volume curves over time by mathematical analysis above 
Furthermore, Figure 8 shows the pressure (blue color curve) and the identified pressure (red color curve) in $\mathrm{cmH} 2 \mathrm{O}$.

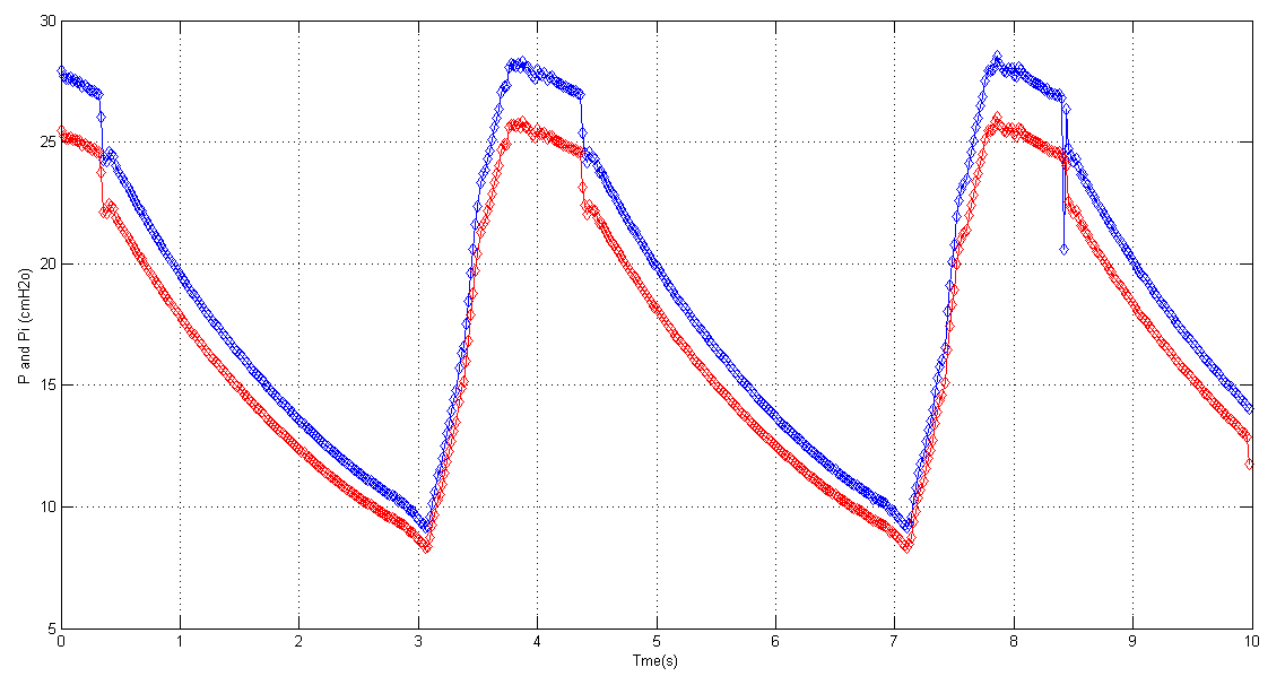

Figure 8. Pressure and identified pressure curves over time by mathematical analysis above

Figure 9 shows the air volume flow (blue color curve) and its identification (red color curve) in 1/min during 10 seconds, it is possible to see that the identified airflow curve can avoid possible disturbances (such as rejecting periodical peaks from the blue color curve).

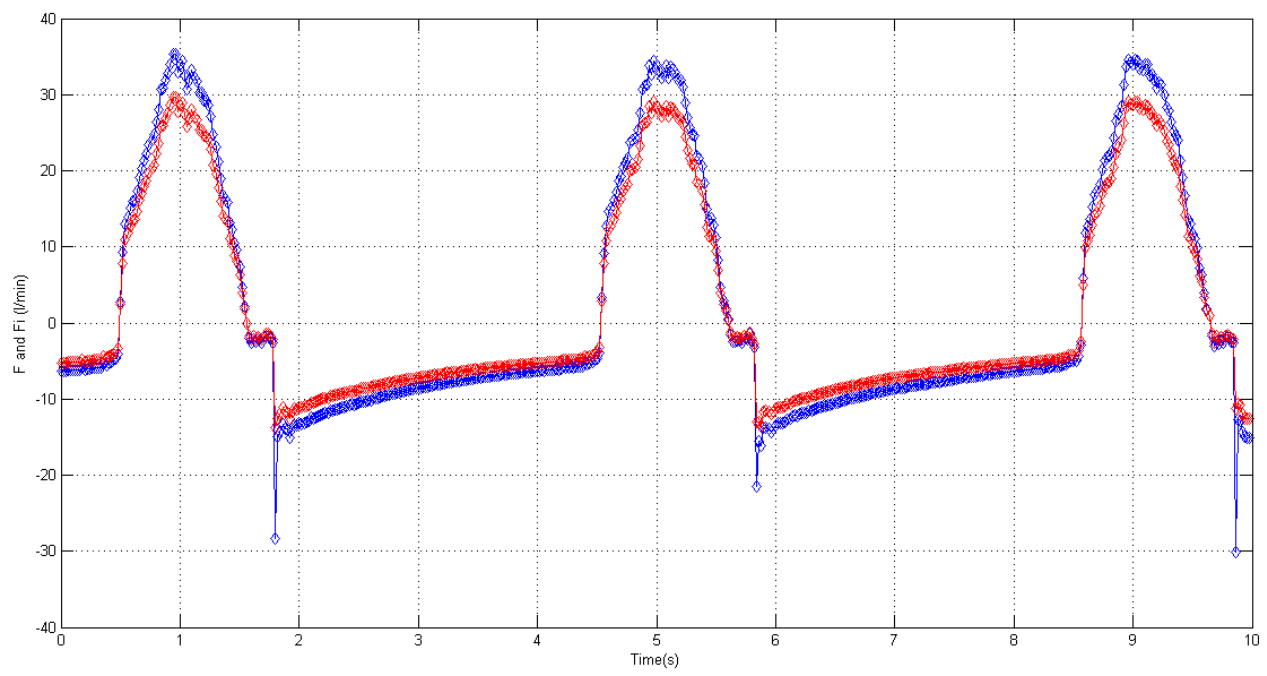

Figure 9. Flow and identified flow curves over time by mathematical analysis above. 
Finally, in Figure $\mathbf{1 0}$ is showed the volume (blue color curve) and its identification (red color curve) in $(\mathrm{mL})$.

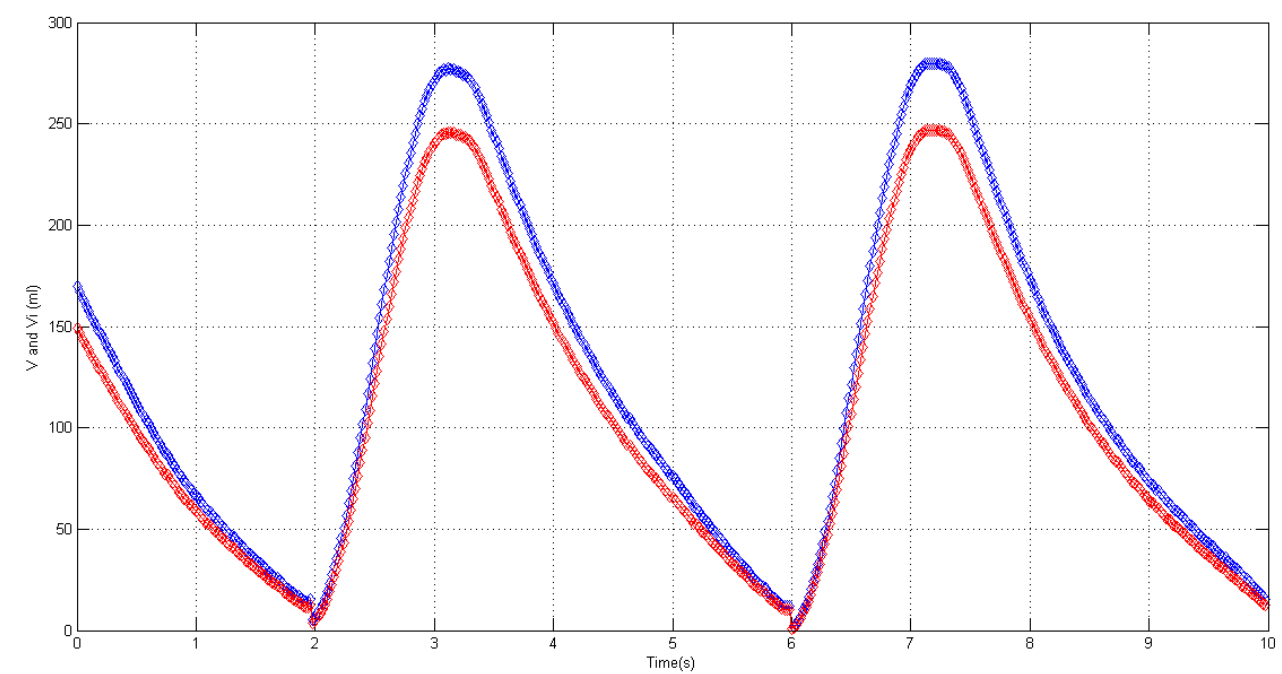

Figure 10. Volume and identified volume curves over time by mathematical analysis above

By another side, the parametric and non-parametric identification analysis, that was made in this research by the adaptive and polynomial analysis from equations o paragraphs above [8], [9], [10], this study let to achieve the performance of the mechanical ventilator through the power consumed and described in Figure 11. In which, the blue color curve is the motor power (W), the red color curve is the inertia power $(\mathrm{W})$ and the green color curve is the total power which is less than the maximal power produced by the motor in maximal load.

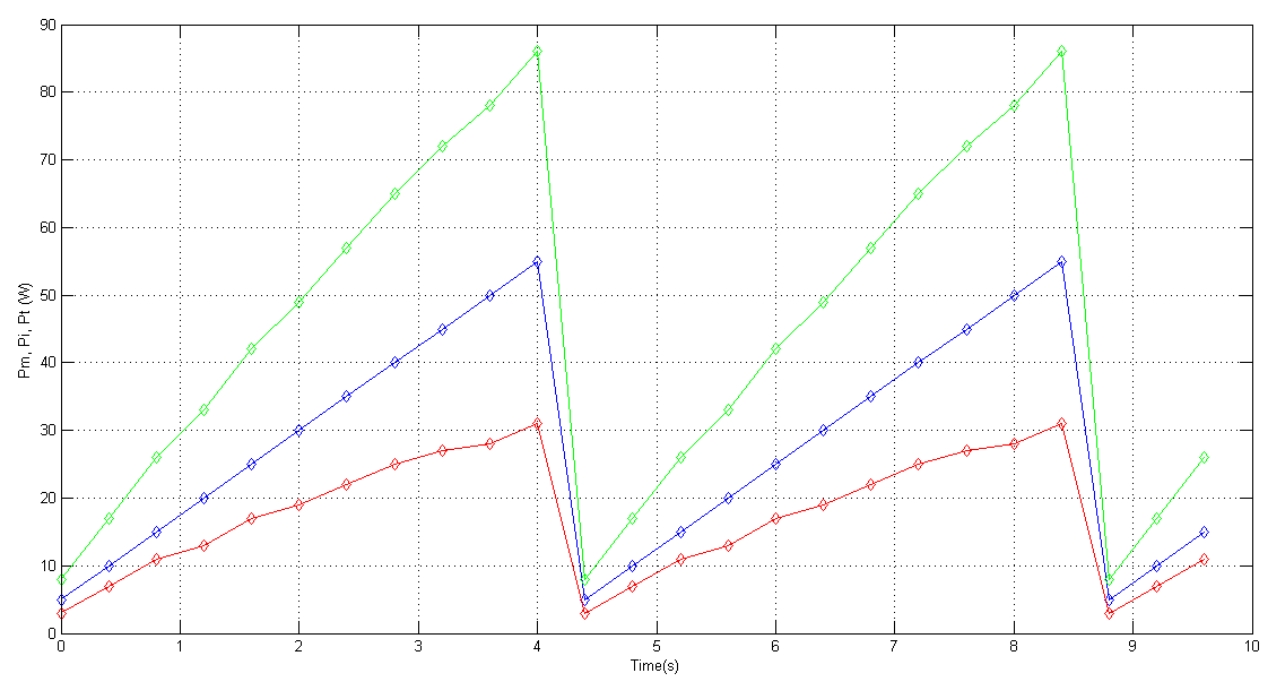

Figure 11. Power analysis of the mechanical ventilator 


\subsection{Ventilation curves estimation based on angular position}

It was evaluated the performance of the mathematical model (after to design the model more appropriated for this mechanical system) through the design of an algorithm to estimate: "air volume, air pressure and airflow" furthermore the estimated parameters were evaluated with the identified parameters by experiments according to enhance the answer of the system. In Figure $\mathbf{1 2}$ is depicted the scheme of the linear equation (achieved as a consequence of the model and algorithm designed) which let to estimate the behavior of the physical variables (volume, pressure and airflow). " $\theta$ " is the angular displacement of the rotor over the airbag, " $R$ " is the reference matrix which contains the desired (theoretical) values of the physical variables, " $\mathrm{A}$ " has the matrix weights to get adaptation and " $\mathrm{E}$ " is the matrix which contains the final estimation.

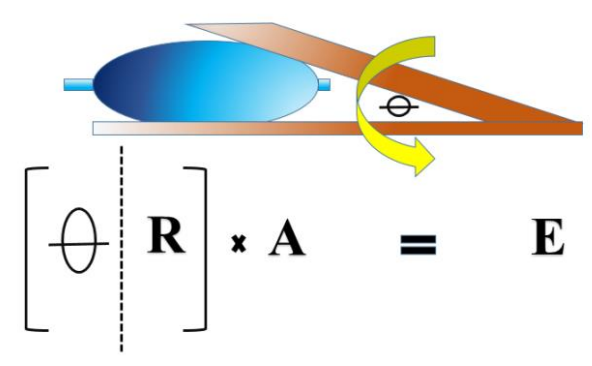

Figure 12. Scheme for estimations with angular position as main input variable

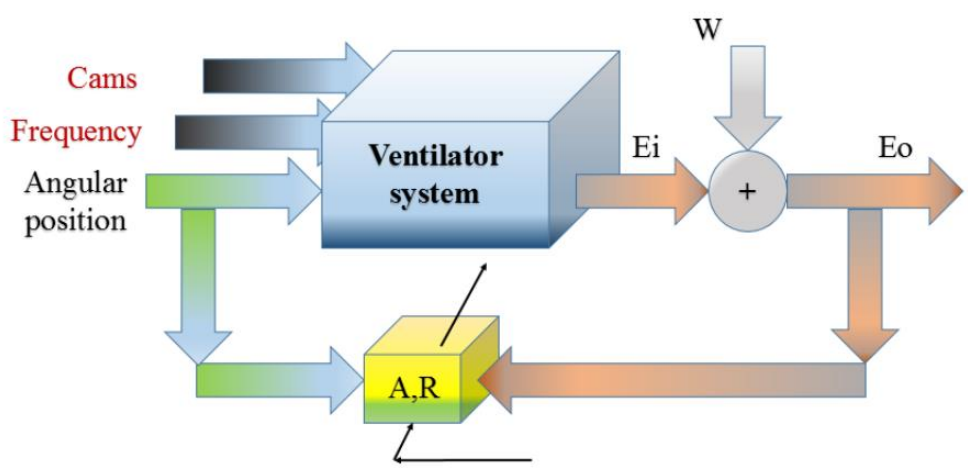

Figure 13. Block diagram for estimations with angular position as main input variable to design sample variables algorithm.

According to find better estimation of the physical variables: "volume, pressure and airflow", it was prepared the mathematical model as dependence of two measurements: "the rotor angle displacement and the differential pressure" that are included in the entrance matrix as reference of the estimation by adaptive weight compensations. That is the reason why in Figure $\mathbf{1 4}$ is depicted the scheme of the entrance variable matrix composed by $\theta$, "P" and " $\mathrm{R}$ " and the adaptive matrix " $\mathrm{A}$ " and the result of estimations given by " $\mathrm{E}$ ". 


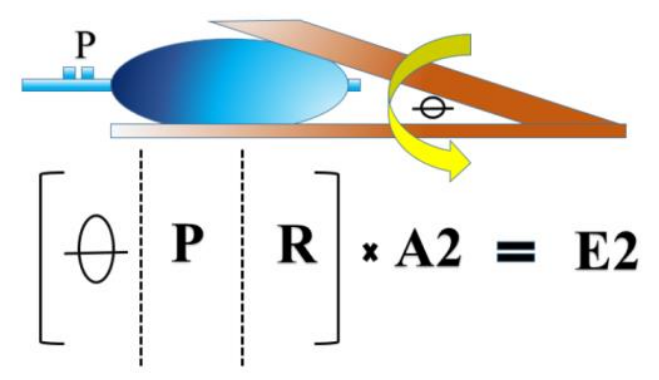

Figure 14. Scheme for estimations with angular position and differential pressure as main input variables.

Moreover, Figure 15 shows the algorithm by graphic representation, in which there are as entrance variables "differential pressure, angular position furthermore the parameter Cams (this is the cam size which is a data introduced by the medical doctor) and the frequency (this is the cam speed value over the airbag, which is a data introduced by the medical doctor)". All these entrance variables and parameters are introduced to the algorithm (designed as a consequence of the mathematical model designed and described in chapters above) the correlation from introduced data with the adaptation matrix " $A$ " and reference matrix " $R$ " achieved the responses matrix " $E$ " which was under correlation with disturbance "W" and the final response matrix "E0".

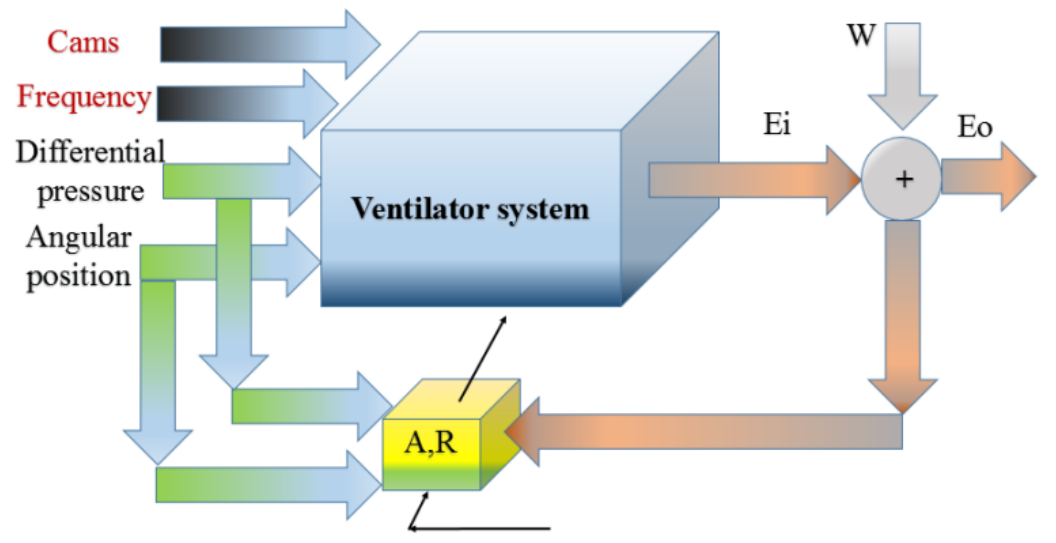

Figure 15. Block diagram for estimations with angular position and differential pressure as main input variables to design sample variables algorithm

\section{Experimental setup}

The mechanical ventilation system OxygenIP.PE was tested in the Biomedical Engineering Laboratory from the Pontificia Universidad Católica del Perú. Figure 16a shows the experimental setup and Figure 16b shows an equivalent scheme of the setup and its components. It consists of the system OxygenIP.PE connected to a medical breathing circuit where a medical gas flow meter Fluke VT650 was installed. An artificial lung Fluke Accu Lung, a precision test lung, was used, it can simulate three conditions: compliance $50 \mathrm{~mL} / \mathrm{cmH} 2 \mathrm{O}$ and resistance $5 \mathrm{cmH} 2 \mathrm{O}-\mathrm{s} / \mathrm{L}$, compliance 20 $\mathrm{mL} / \mathrm{cmH} 2 \mathrm{O}$ and resistance $20 \mathrm{cmH} 2 \mathrm{O}-\mathrm{s} / \mathrm{L}$ and compliance $10 \mathrm{~mL} / \mathrm{cmH} 2 \mathrm{O}$ and resistance $50 \mathrm{cmH} 2 \mathrm{O}$ $\mathrm{s} / \mathrm{L}$. For each condition, all the cam sizes were tested during 2 minutes per cam size and the ventilation curves air volume, pressure and flow over time were obtained. 


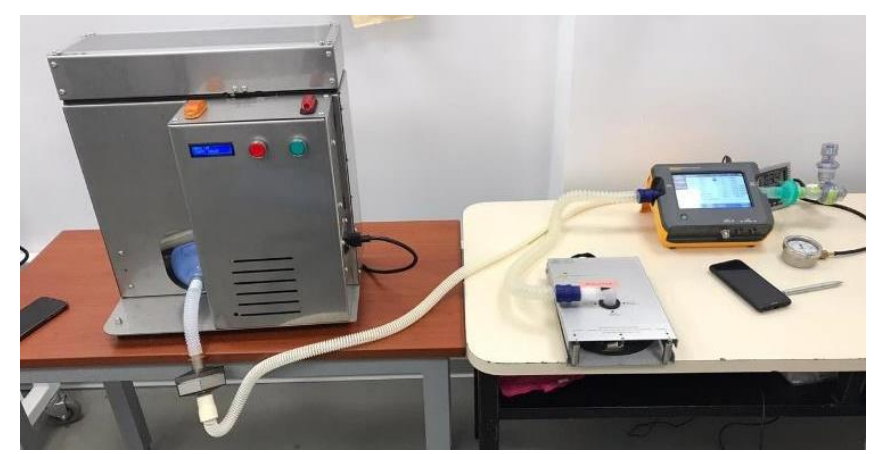

(a)

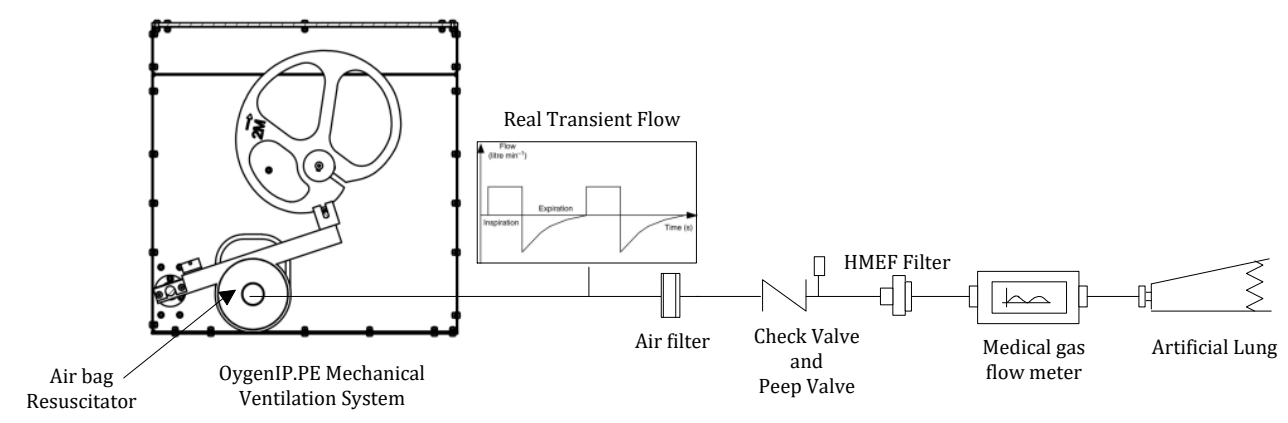

(b)

Figure 16. (a) Experimental setup of the mechanical ventilation system OxygenIP.PE validation at the Bioengineering Laboratory from the Pontificia Universidad Católica del Perú; (b) Scheme of the experimental setup

\section{Results and discussion}

\subsection{Experimental ventilation curves}

The mechanical ventilation system OxygenIP.PE was tested for 2 minutes for each cam. A medical flow meter was used for measuring ventilation curves and the results are shown in Figure 17, Figure 18 and Figure 19 for the different characteristics of the artificial lung.

Figure 17 shows the ventilation curves for the five cams in a breathing circuit with an implemented artificial lung of a compliance $50 \mathrm{~mL} / \mathrm{cmH} 2 \mathrm{O}$ and resistance of $5 \mathrm{cmH} 2 \mathrm{O}-\mathrm{s} / \mathrm{L}$. The minimum and maximum air volume over time are obtained by using the minimum cam size XS and maximum cam size $\mathrm{XL}$, respectively; the same behavior occurs with the pressure and flow over time. Also the relation between the ventilation variables: volume, pressure and flow are manifested according to the cam size, a higher cam size produces a higher value of the ventilation curves for the same lung characteristics. This is because a higher cam size produces a higher compression of the airbag resuscitator, hence a higher pressure value is produced in the breathing circuit. It is known that compliance and resistance of the lung produces a resistance pressure, also the difference between the airbag pressure and the resistance pressure produces the airflow to the patient; in this sense, ventilation curves increase in value over time. 

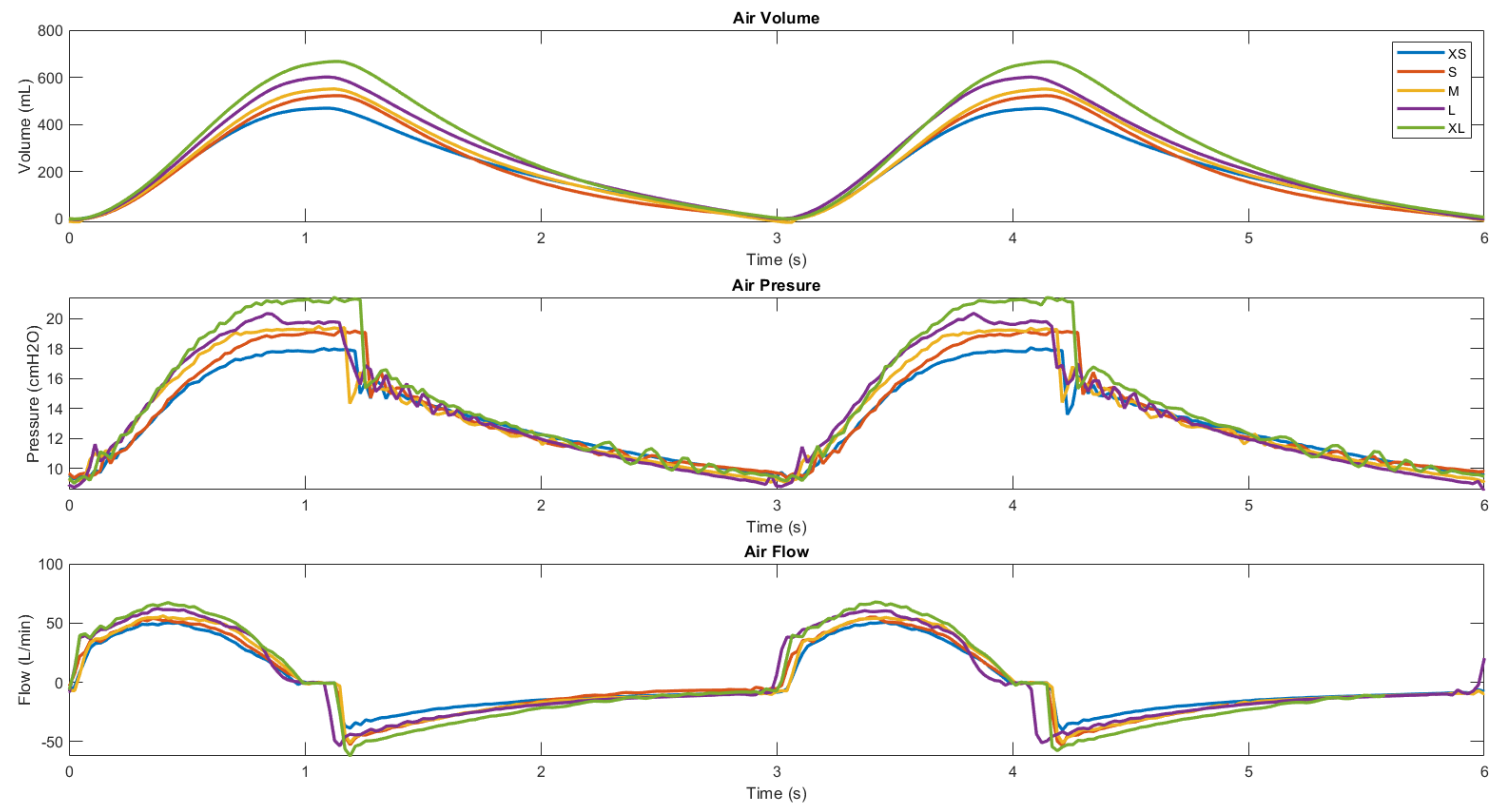

Figure 17. Air volume, pressure and flow curves over time for a lung with compliance $50 \mathrm{~mL} / \mathrm{cmH} 2 \mathrm{O}$ and resistance $5 \mathrm{cmH} 2 \mathrm{O}-\mathrm{s} / \mathrm{L}$

Figure 18 and Figure 19 show the ventilation curves for a patient with a lung in two conditions; a partially damaged lung with a compliance $20 \mathrm{~mL} / \mathrm{cmH} 2 \mathrm{O}$ and resistance $20 \mathrm{cmH} 2 \mathrm{O}-\mathrm{s} / \mathrm{L}$, and a completely damaged lung with a compliance $10 \mathrm{~mL} / \mathrm{cmH} 2 \mathrm{O}$ and resistance $50 \mathrm{cmH} 2 \mathrm{O}-\mathrm{s} / \mathrm{L}$. For each lung condition, it can be noted that the shape and relation of the ventilation curves maintain the same behavior as explained before and ventilation values volume, pressure and flow continues increasing while the cam size increases. However, a damaged condition of the lung produces the minimum ventilation values of air volume and flow over time. This is due to the compliance and resistance of the lung which increases the resistance pressure if the lung damage increases, hence the pressure inside the airbag also has to increase in order to provide air flow to the patient; this is why the maximum pressure is obtained for the damaged lung condition. 

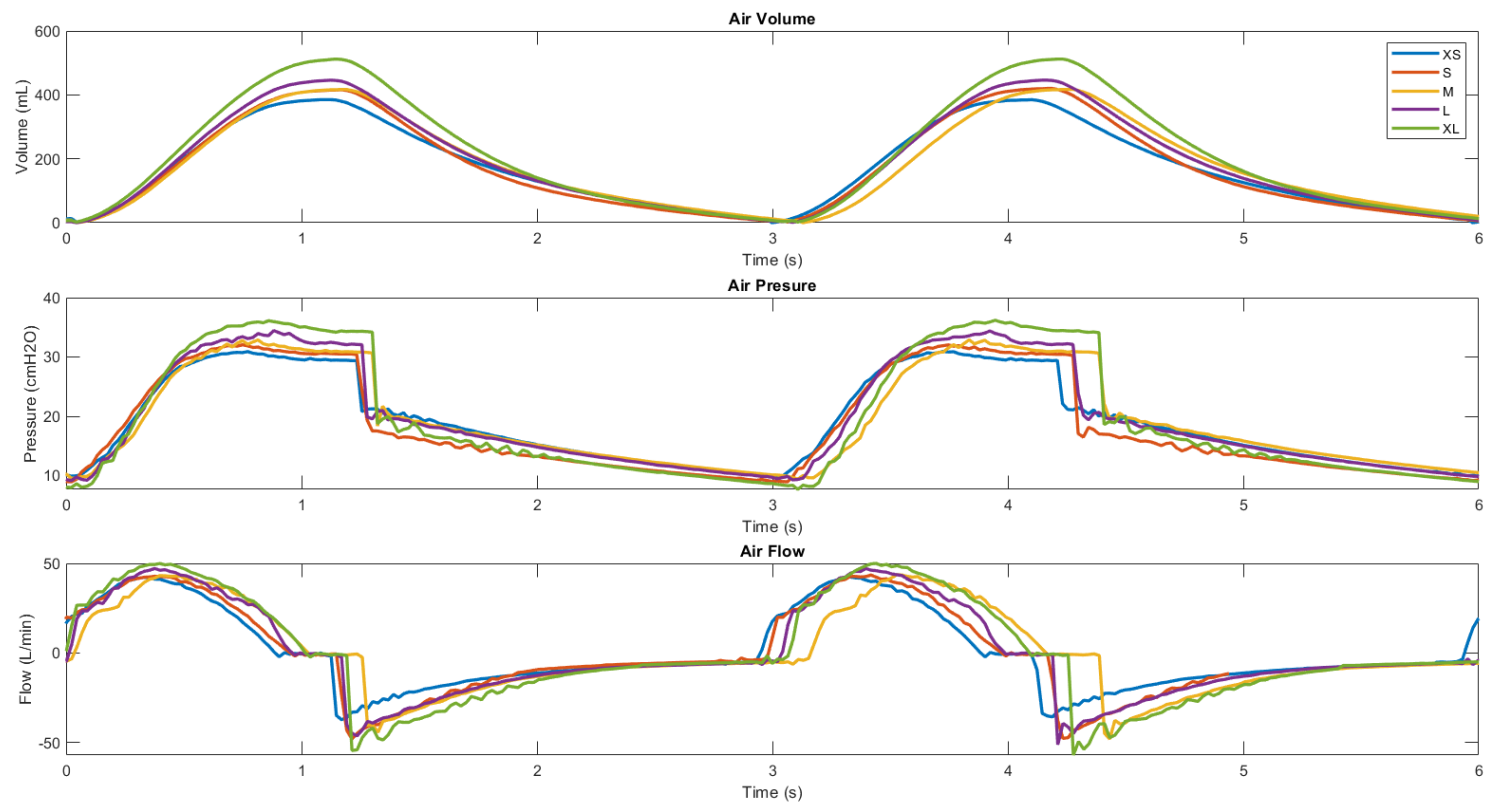

Figure 18. Air volume, pressure and flow curves over time for a lung with compliance $20 \mathrm{~mL} / \mathrm{cmH} 2 \mathrm{O}$ and resistance $20 \mathrm{cmH} 2 \mathrm{O}-\mathrm{s} / \mathrm{L}$
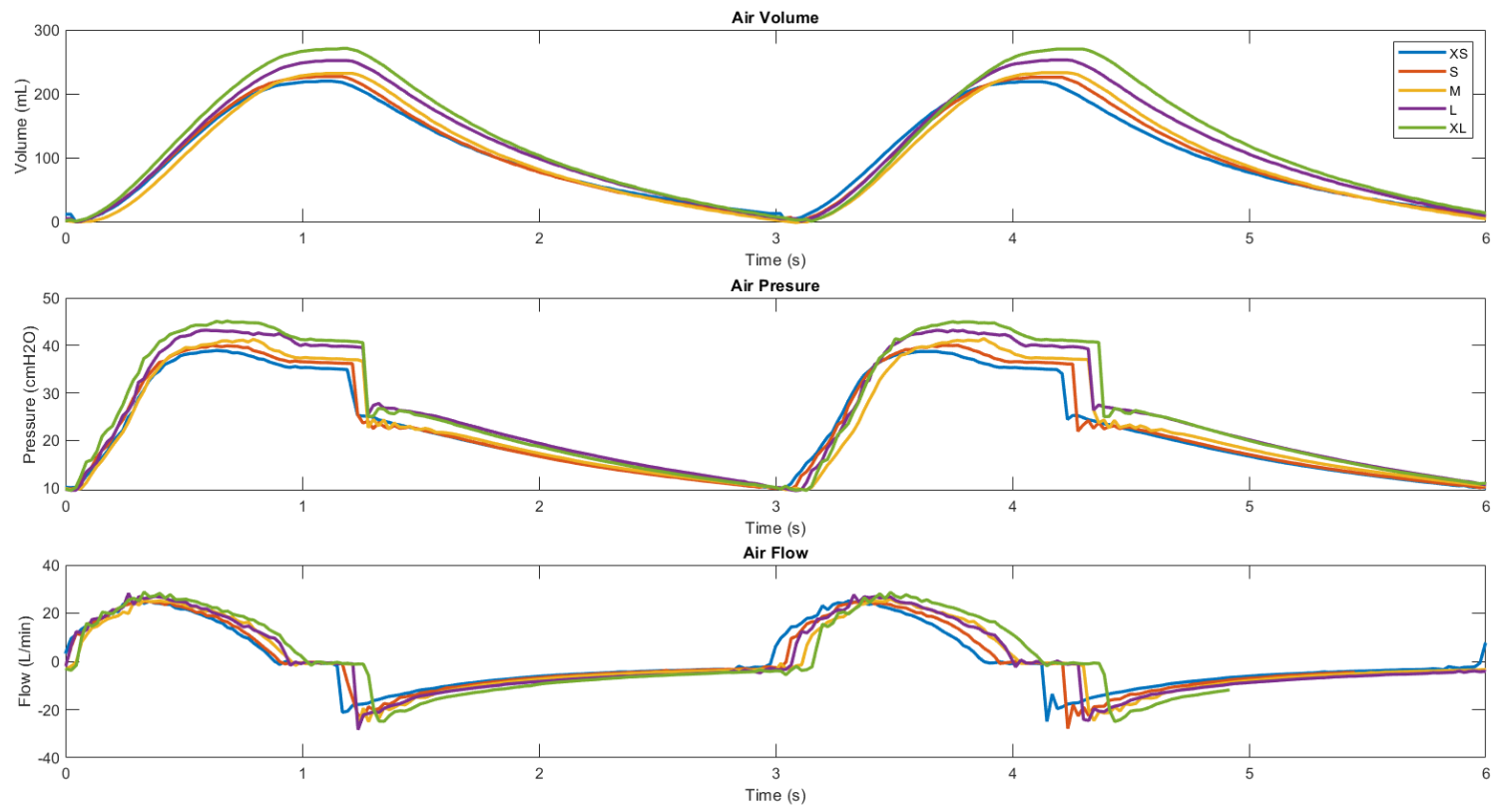

Figure 19. Air volume, pressure and flow curves over time for a lung with compliance $10 \mathrm{~mL} / \mathrm{cmH} 2 \mathrm{O}$ and resistance $50 \mathrm{cmH} 2 \mathrm{O}-\mathrm{s} / \mathrm{L}$

It's necessary to represent the characteristics of the ventilation curves for the different possible conditions, either for different cams sizes or lung conditions to help medical staff who select the proper cam size for a particular patient. In this sense, Figure 20 shows the highest values of the ventilation curves for each cam size and lung condition. For the same lung condition, air volume, pressure and flow increase while the cam size increase as explained before. However, this values decreases significantly for a damaged lung condition; for the minimum cam size the air tidal volume 
decreases to $46.91 \%$ when the lung is damaged(compliance $10 \mathrm{~mL} / \mathrm{cmH} 2 \mathrm{O}$ and resistance $50 \mathrm{cmH} 2 \mathrm{O}$ $\mathrm{s} / \mathrm{L}$ ), while for the maximum cam size $\mathrm{XL}$, the air volume decreases to $40.65 \%$ its value.
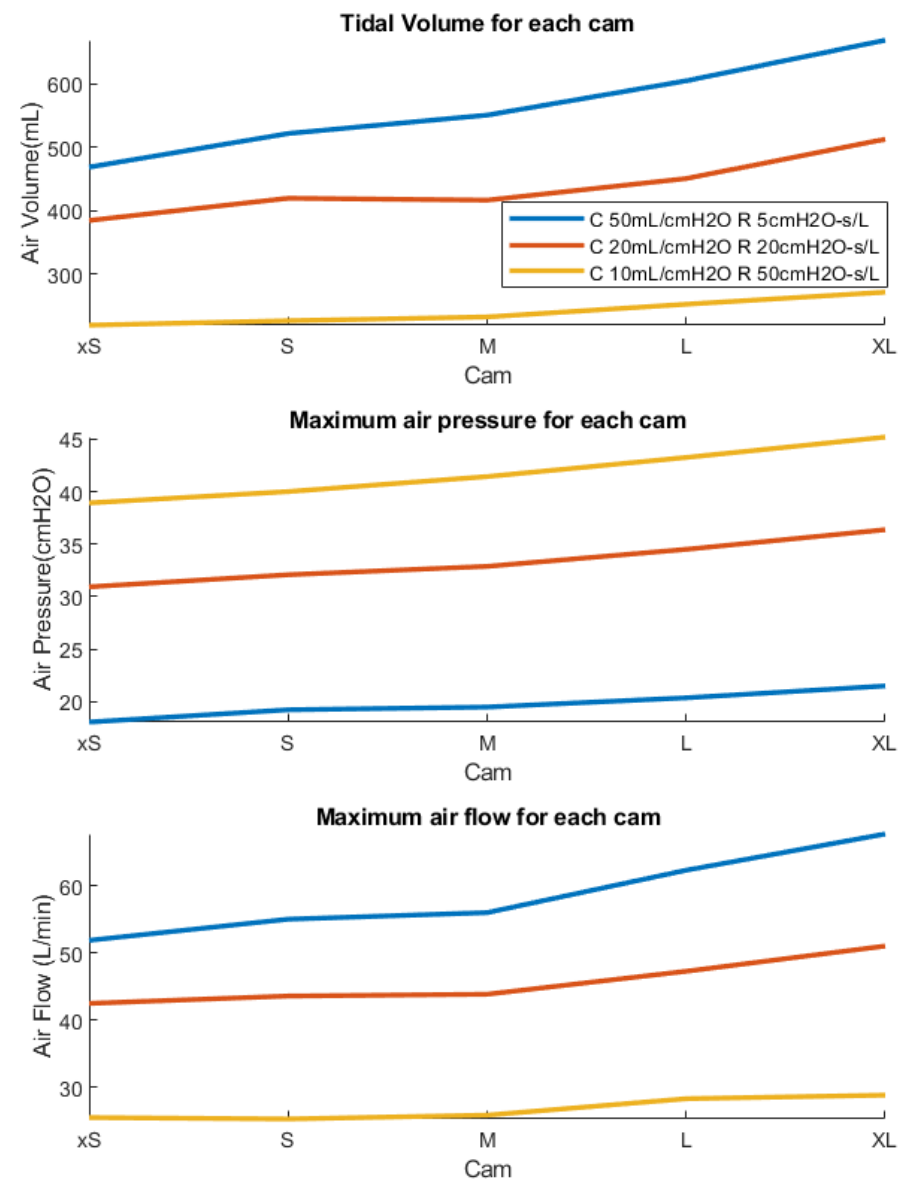

Figure 20. Characteristic ventilation curves for each cam of the OxygenIP.PE mechanical ventilation system

Moreover, according to enhance the identified answer of the system (for every variable: pressure, airflow and volume) it was developed the prediction analysis through adaptive coefficients in the polynomial model. Hence, in Figure $\mathbf{2 1}$ is showed the measured pressure (blue color curve), the identified pressure (red color curve) and the adaptive-predictive pressure (green color curve) in $\mathrm{cmH} 2 \mathrm{O}$. 


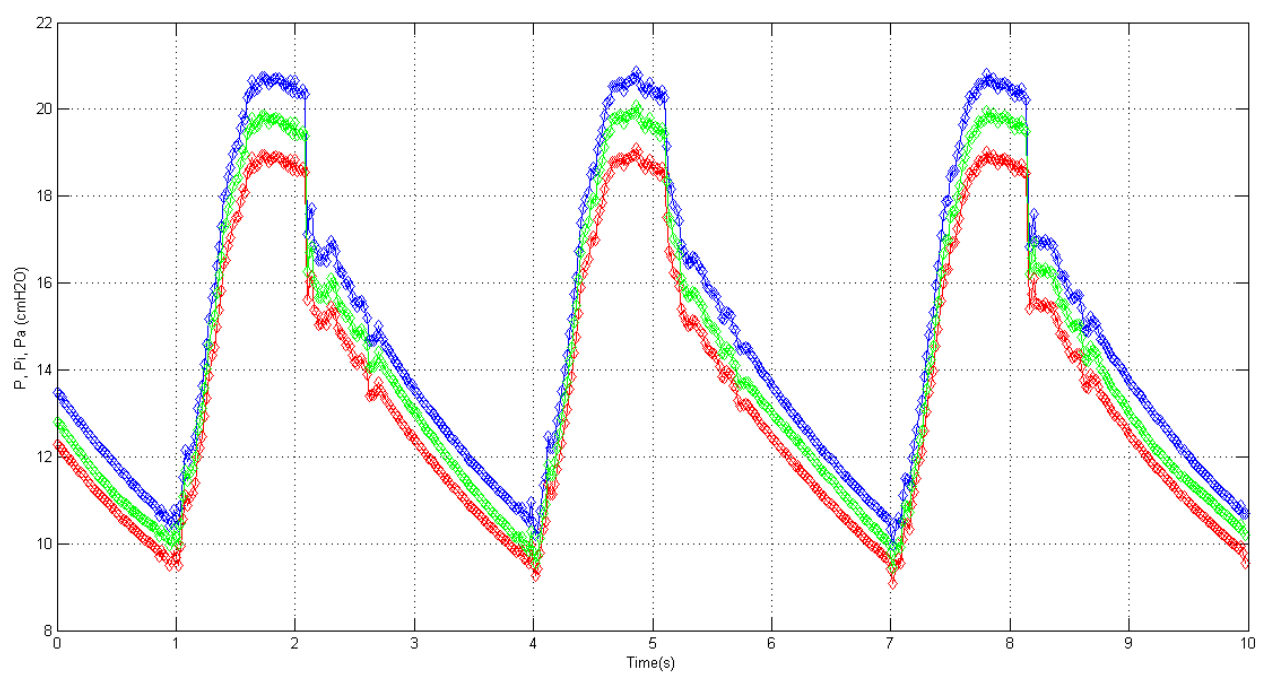

Figure 21. Measured pressure, identified pressure and adaptive-predictive pressure.

In Figure 22 is showed the measured airflow (blue color curve), the identified airflow (red color curve) and the adaptive-predictive airflow (green color curve) in litters per minute.

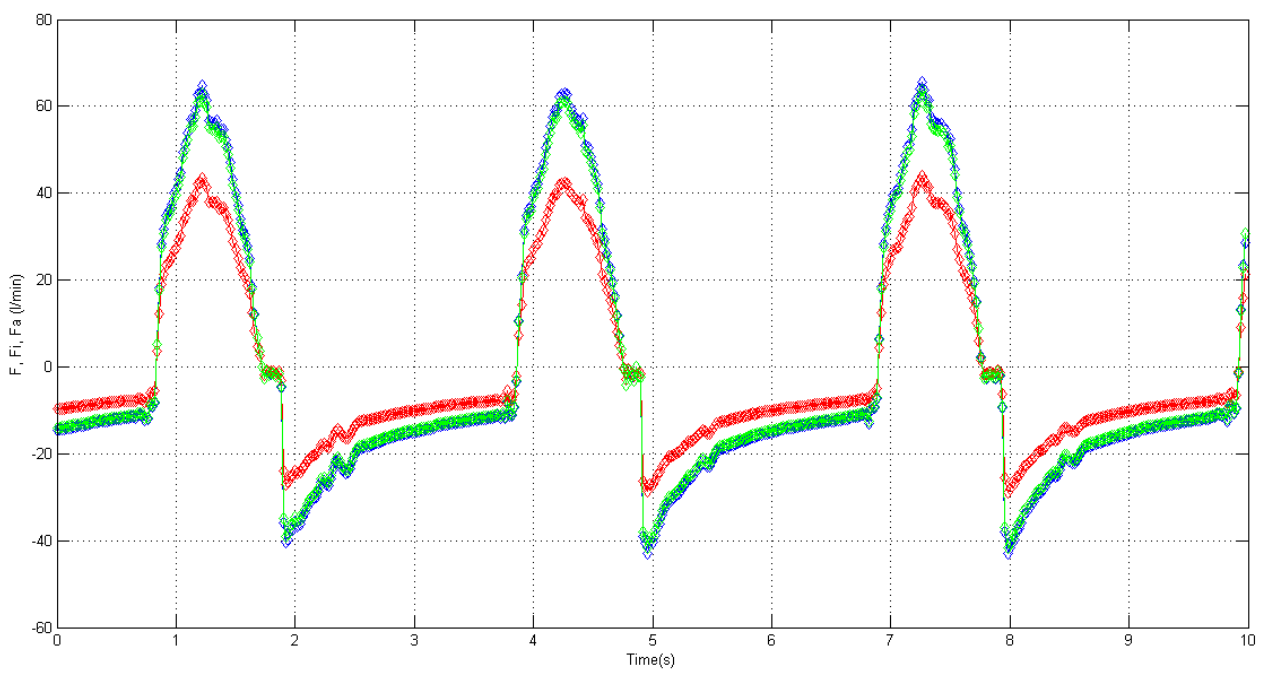

Figure 22. Measured airflow, identified airflow and adaptive-predictive airflow.

In Figure $\mathbf{2 3}$ is showed the measured volume (blue color curve), the identified volume (red color curve) and the adaptive-predictive volume (green color curve) in $\mathrm{mL}$. 


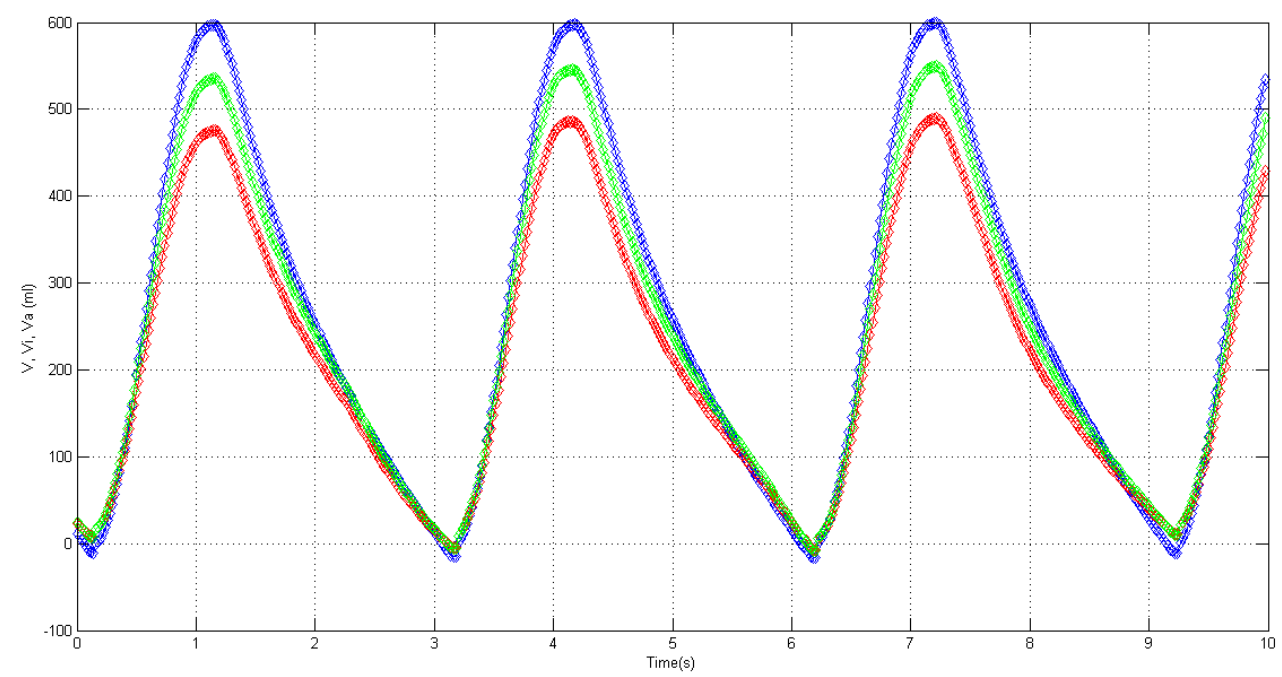

Figure 23. Measured volume, identified volume and adaptive-predictive volume.

\subsection{Ventilation curves predicion based on the mathematical model}

In Figure 24, it is depicted the measured pressure as reference (curve in blue color), the identified pressure (curve in red color) and the adaptive-predictive pressure (curve in green color), moreover, it is shown the rotor angle displacement (curve in violet color) and the differential pressure (curve in yellow color) given by integrated circuit "IC". Hence, the pressure estimation (because of adaptiveprediction) is obtained as consequence of the rotor angle displacement and differential pressure, even though the out of phase half cycle approximately between the reference pressure with the estimated and identified curves.

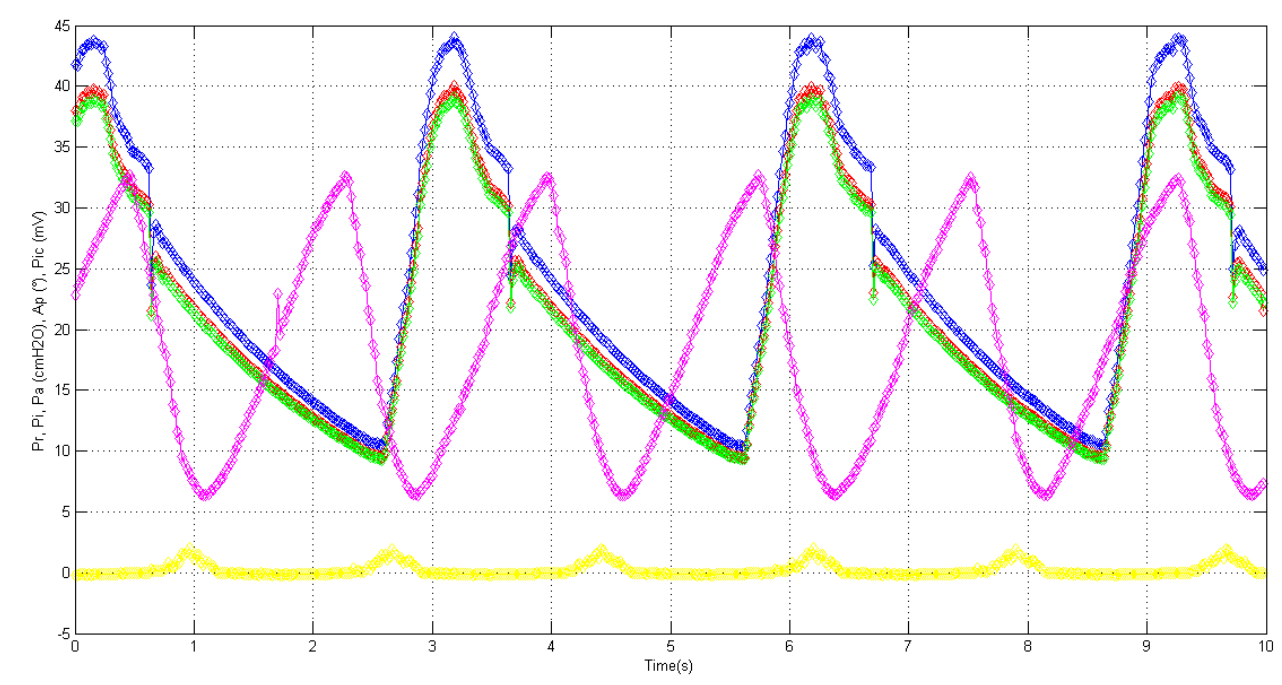

Figure 24. Pressure estimations

In Figure 25, it is depicted the measured volume as reference (curve in blue color), the identified volume (curve in red color) and the adaptive-predictive volume (curve in green color), moreover, it is shown the rotor angle displacement (curve in violet color) and the differential pressure (curve in 
yellow color) given by integrated circuit "IC". Hence, the volume estimation (because of adaptiveprediction) is obtained as consequence of the rotor angle displacement and differential pressure, even though the out of phase half cycle approximately between the reference volume with the estimated and identified curves.

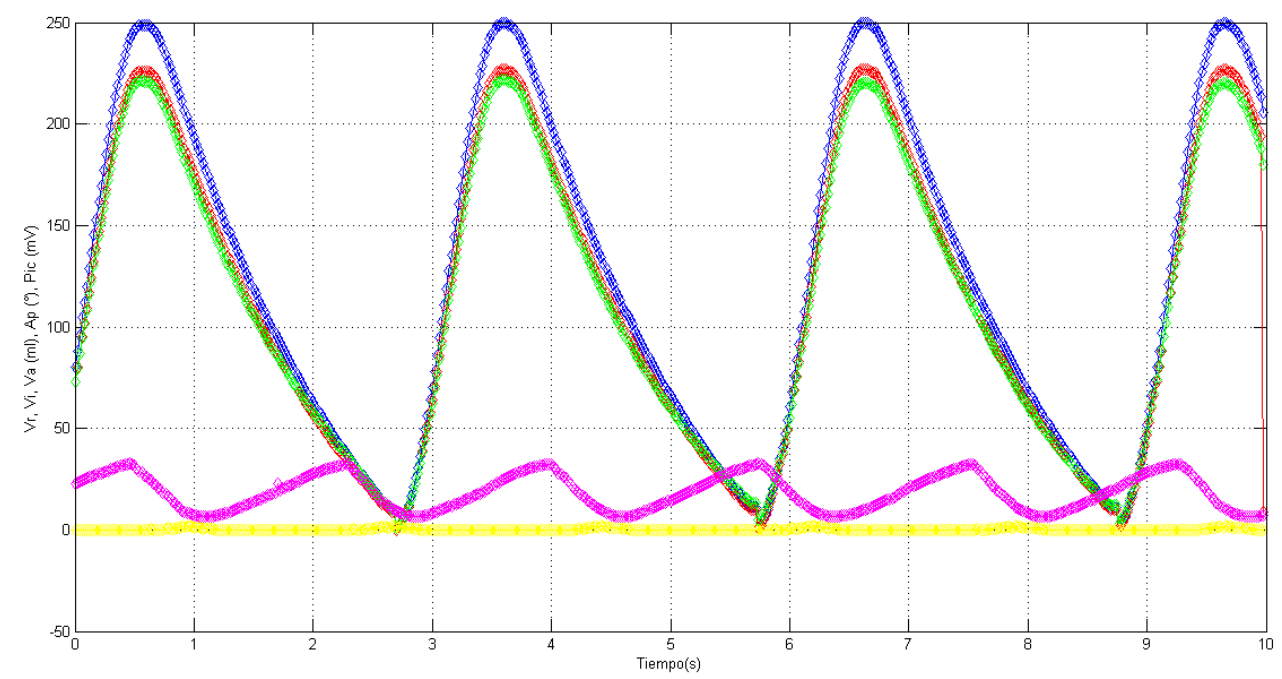

Figure 25. Volume estimations.

In Figure 26, it is depicted the measured airflow as reference (curve in blue color), the identified airflow (curve in red color) and the adaptive-predictive airflow (curve in green color), moreover, it is shown the rotor angle displacement (curve in violet color) and the differential pressure (curve in yellow color) given by integrated circuit "IC". Hence, the airflow estimation (because of adaptiveprediction) is obtained as consequence of the rotor angle displacement and differential pressure, even though the out of phase half cycle approximately between the reference airflow with the estimated and identified curves.

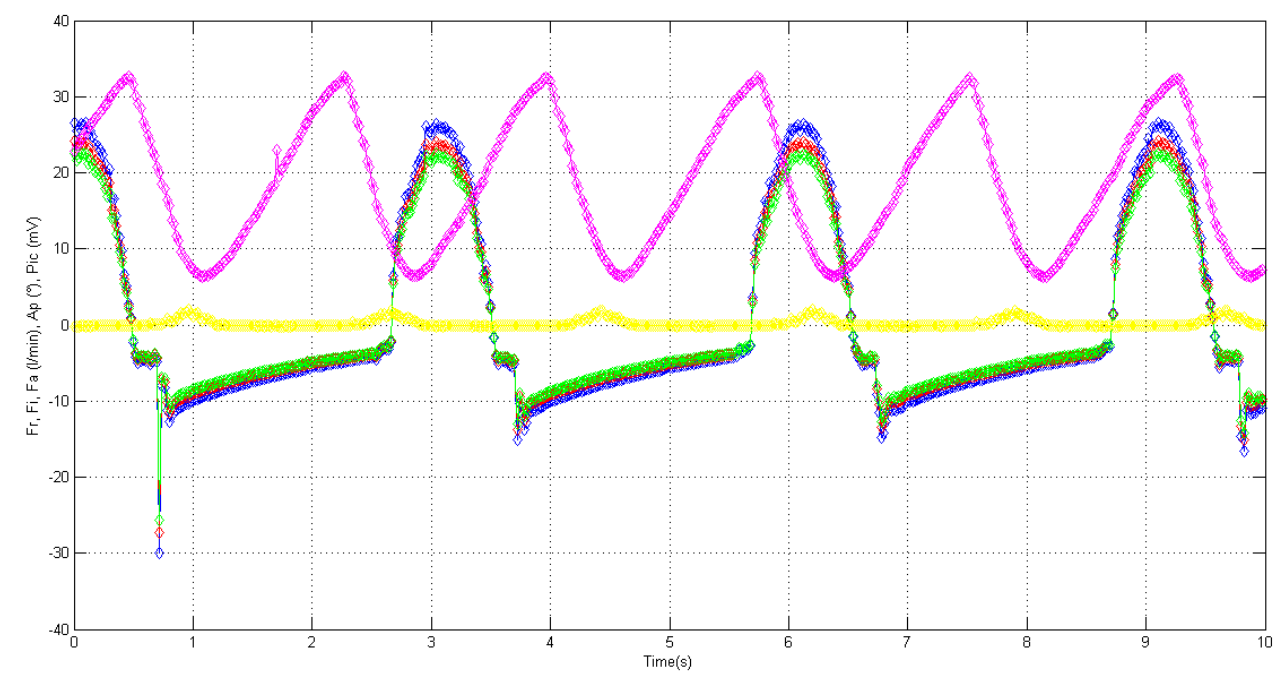

Figure 26. Air flow estimations 


\section{Conclusions}

The mechanical ventilation system OxygenIP.PE is a redesign in order to satisfy the requirements of a different country, (in this case, Peru), using different a power source and airbag resuscitator which change ventilation curves produced by the ventilation system due to its different properties, capacity, geometry and dimensions. Some components were also upgraded to allow for mass production using local technology, a longer lifetime and improvement of performance in terms of friction, vibration and noise reduction. Ventilation curves produced by the OxygenIP.PE maintains a same behavior and magnitude as the original design. This suggests a mechanical ventilation system able to be medically validated by the government in an emergency context if there aren't conventional mechanical ventilators availability.

The control algorithm developed maintains a previous set rotation frequency of the system over time in spite of variations of system requirements due to its operation. Torque and rotation provided by the DC motor changes over time depending what the system needs, a high cam size for a high air volume increase the torque needed or the own transient nature of the ventilations curves changes the operation over time. In this sense, the control algorithm is able to provide a determined current calculated over time to control the response of the mechanical ventilation system OxygenIP.PE, which assures a correct working needed for a medical equipment.

It was designed a mathematical model to estimate and to identify the physical variables and geometrical parameters of the mechanical ventilator prepared by cams. It was designed a monitoring algorithm according to visualize the identified and estimated physical variables: "pressure, volume and airflow". The mechanical ventilator, as a consequence of the mathematical model and monitoring algorithm designed, can proportionate the estimation of the "pressure, volume and airflow" from the correlation of the angular position of the oscillating follower pivot. This is measured over time by the sensors implemented. Furthermore, by measuring differential pressure, it was possible to estimate better way the volume and airflow.

Finally, the mechanical ventilation system OxygenIP.PE is still a low cost equipment, sturdier and more sophisticated than the original able to be fabricated in mass in Peru regardless import availability of special electronic components.

Author Contributions: Conceptualization, J.A.C.Ch., J.J.J.F. and C.G.R.R.; methodology, J.A.C.Ch., J.J.J.F. and C.G.R.R.; software, J.A.C.Ch., C.G.R.R. and .B.J.M.A.C.; formal analysis, J.A.C.Ch. and C.G.R.R.; investigation, J.A.C.Ch. and C.G.R.R.; resources, J.A.C.Ch., J.J.J.F., C.G.R.R. and B.J.M.A.C.; data curation, J.A.C.Ch.; writingoriginal draft preparation, J.A.C.Ch.; writing - review and editing, J.A.C.Ch., J.J.J.F and C.G.R.R.; visualization, J.A.C.Ch., C.G.R.R. and B.J.M.A.C.; supervision, J.J.J.F.; project administration, J.J.J.F.; funding acquisition, J.J.J.F. All authors have read and agreed to the published version of the manuscript.

Funding: This research was funded by FONDECYT from “Consejo Nacional de Ciencia, Tecnología e Innovación Tecnológica (CONCYTEC), Perú"

Acknowledgments: Authors would like to express theirs special thanks of gratitude to Protofy team, who shared their knowledge and experience of the OxyGEN project development, and also to Andrea Portal, Juan José Leyton and Romel Rosales, whose machine design experience and creativity improved the design procedure of the mechanical ventilation system OxygenIP.PE.

Conflicts of Interest: The authors declare no conflict of interest. The funders had no role in the design of the study; in the collection, analyses, or interpretation of data. 


\section{References}

1. Niggebrügge, H.C. Die Geschichte der Beatmung - Analyse und Neubewertung am Beispiel der Geschichte des "Pulmotor “ Notfallbeatmungs- und Wiederbelebungsgeräts der Lübecker Drägerwerke. 2011.

2. COVID-19 Map - Johns Hopkins Coronavirus Resource Center Available online: https://coronavirus.jhu.edu/map.html (accessed on Nov 25, 2020).

3. Mohsen Al Husseini, A.; Ju Lee, H.; Negrete, J.; Powelson, S.; Tepper Servi, A.; Slocum, A.H. Design and prototyping of a low-cost portable mechanical ventilator. J. Med. Devices, Trans. ASME 2010, 4, 1-1, doi:10.1115/1.3442790.

4. CLÍNIC BARCELONA Available online: https://www.clinicbarcelona.org/noticias/eldispositivo-de-ventilacion-de-emergencia-desarrollado-por-clinic-germans-trias-i-pujol-yub-con-protofy-xyz-recibe-la-aprobacion-de-la-aemps-para-hacer-un-estudio-clinico (accessed on May 15, 2020).

5. OxyGEN Project Available online: https://www.oxygen.protofy.xyz/download (accessed on Nov 23, 2020).

6. OxyGEN Project: Cam shaft design Available online: https://www.oxygen.protofy.xyz/post/cam-shaft-design (accessed on May 15, 2020).

7. Х Халилов, И.А.; Керимов, С.Х.; Багироваgol, С.А.; Гаджиева, Ф.Ш. контактной прочности. 2017.

8. Aldoghaiter, A.; Liu, D.; Laleg-kirati, T.-M. Modulating functions based algorithm for the estimation of the coeficients and differentiation order for a space-fractional advectiondispersion equation. SIAM J. SCI. Comput 2015, 37.

9. Pearson, A.E. Aerodynamic Parameter Estimation Via Fourier Modulating Function Techniques. 1995.

10. Calderón, J.A.; Barriga, E.B.; Mas, R.; Chirinos, L.; Barrantes, E.; Alencastre, J.; Tafur, J.C.; Melgarejo, O.; Lozano, J.H.; Heinrich, B.; et al. Magnetic Bearing Proposal Design for a General Unbalanced Rotor System enhanced because of using sensors/actuators based in nanostructures. E3S Web Conf. 2019, 95, doi:10.1051/e3sconf/20199501002. 